\title{
Management of Chronic Hand and Foot Eczema. An Australia/New Zealand
}

\section{Clinical Narrative.}

Marius Rademaker ${ }^{1}$ | Katherine Armour ${ }^{2}$ | Christopher Baker ${ }^{2,3}$ | Peter Foley ${ }^{2,3}$ | Kurt Gebauer ${ }^{4,5}$ | Monisha Gupta6,7 | Gillian Marshman ${ }^{8}$ | Alicia O'Connor ${ }^{7}$ |

Diana Rubel ${ }^{9,10}$ | John Sullivan ${ }^{11}$ | Li-Chuen Wong ${ }^{12}$

1 Waikato Clinical Campus, University of Auckland's Faculty of Medical and Health Sciences, Hamilton, New Zealand,

${ }^{2}$ Skin Health Institute, Carlton, Victoria,

${ }^{3}$ St Vincent's Hospital Melbourne, The University of Melbourne, Fitzroy, Victoria

${ }^{4}$ University of Western Australia, Perth, Western Australia

${ }^{5}$ Probity Medical Research, Freemantle, Western Australia,

${ }^{6}$ Department of Dermatology, Liverpool Hospital, Sydney, New South Wales

7 The Skin Hospital, Darlinghurst, New South Wales

${ }^{8}$ Flinders Medical Centre, Flinders University Medical School, Adelaide, South

Australia,

${ }^{9}$ Woden Dermatology, Canberra, Australian Capital Territory,

${ }^{10}$ Australian National University, Canberra, Australian Capital Territory,

11 The Sutherland Hospital, Caringbah, New South Wales, University of New South Wales

12 The Children's Hospital at Westmead, Sydney, New South Wales, Australia

Address for correspondence: Hon. Associate Professor Marius Rademaker, Waikato Clinical Campus, University of Auckland's Faculty of Medical and Health Sciences, Hamilton, New Zealand

Tel: +6478381035

Email: Rademaker@xtra.co.nz

- Short title: Management of hand/foot eczema

This is the author manuscript accepted for publication and has undergone full peer review but has not been through the copyediting, typesetting, pagination and proofreading process, which may lead to differences between this version and the Version of Record. Please cite this article as doi: 10.1111/AJD.13418

This article is protected by copyright. All rights reserved 
- Word Count: 4725

- References: 94

- Tables: 0 , but a list of key points that could be made into a table

- Figures: 0

- Key words: hand eczema, foot eczema, chronic hand dermatitis, second line therapy, systemic treatment, corticosteroids, ciclosporin, acitretin, alitretinoin,

- phototherapy

Ethics: not necessary

Acknowledgments: We are very grateful to AbbVie Pty Ltd (Australia) for an unrestricted educational grant. They had no influence in the subject matter, discussion or writing up. We are grateful for Tony James, independent medical writer for taking notes during the meeting. He was not otherwise involved in the preparation of this manuscript.

Authorship:

- Design, literature search, discussion, conclusions, final version of manuscript

$$
\begin{aligned}
& \text {-all authors } \\
& \text { - Manuscript preparation - MR } \\
& \text { - Final manuscript - all authors }
\end{aligned}
$$

Conflicts of Interest:

\begin{tabular}{|l|l|}
\hline Rademaker & Clinical investigator for AbbVie and Douglas Pharmaceuticals \\
\hline Armour & $\begin{array}{l}\text { Speaker and/or member of advisory boards for AbbVie, Janssen-Cilag, } \\
\text { Novartis and Sun Pharma }\end{array}$ \\
\hline Baker & $\begin{array}{l}\text { Clinical Investigator, speaker and/or advisory board: AbbVie, Janssen, } \\
\text { Novartis, Pfizer }\end{array}$ \\
\hline Foley & $\begin{array}{l}\text { Consultant, investigator, speaker and/or advisor for and/or received travel } \\
\text { grants: 3M/iNova/Valeant, Abbott/AbbVie, Amgen, Biogen Idec, BMS, } \\
\text { Boehringer Ingelheim, Celgene, Celtaxsys, Cutanea, Dermira, Eli Lilly, } \\
\text { Galderma, GSK/Stiefel, Janssen, LEO/Peplin, Novartis, Regeneron, Sanofi } \\
\text { Genzyme, Schering-Plough/MSD, Sun Pharma, UCB, and Wyeth/Pfizer }\end{array}$ \\
\hline Gebauer & \begin{tabular}{l} 
Clinical investigator and/or Advisory Board: AbbVie, Celgene, Janseen, Eli Lilly \\
\hline
\end{tabular}
\end{tabular}




\begin{tabular}{|l|l|}
\hline Gupta & None \\
\hline Marshman & Clinical investigator for AbbVie and Novartis \\
\hline O’Connor & None \\
\hline $\begin{array}{l}\text { Rubel } \\
\text { Sullivan }\end{array}$ & $\begin{array}{l}\text { Clinical Investigator and/or Advisory Board: AbbVie, Amgen, Boehringer- } \\
\text { Ingelheim, Celgene, Eli Lilly, Janssen, Novartis, Sun Pharma }\end{array}$ \\
\hline Wong & None \\
\hline
\end{tabular}

Name/Degree/Affiliation

\begin{tabular}{|l|l|l|}
\hline Name & $\begin{array}{l}\text { Highest } \\
\text { Degree }\end{array}$ & Affiliation/Address \\
\hline Rademaker & DM FRCP & $\begin{array}{l}\text { Waikato Clinical School, Auckland University Medical } \\
\text { School, Hamilton, New Zealand }\end{array}$ \\
\hline Armour & FACD & Skin Health Institute, Carlton, Victoria, Australia \\
\hline Baker & FACD & $\begin{array}{l}\text { Skin Health Institute, Carlton, Victoria; and St Vincent's } \\
\text { Hospital Melbourne, The University of Melbourne, Fitzroy, } \\
\text { Victoria, Australia }\end{array}$ \\
\hline Foley & MD FACD & $\begin{array}{l}\text { Skin Health Institute, Carlton, Victoria; and St Vincent's } \\
\text { Hospital Melbourne, The University of Melbourne, Fitzroy, } \\
\text { Victoria, Australia }\end{array}$ \\
\hline Gebauer & FACD & $\begin{array}{l}\text { University of Western Australia, Perth; and Probity Medical } \\
\text { Research, Freemantle, WA, Australia }\end{array}$ \\
\hline Gupta & FACD & $\begin{array}{l}\text { Department of Dermatology, Liverpool Hospital, Sydney, New } \\
\text { South Wales; and The Skin Hospital, Darlinghurst, New South } \\
\text { Wales }\end{array}$ \\
\hline Marshman & FACD & $\begin{array}{l}\text { Flinders Medical Centre, Flinders University Medical School, } \\
\text { Adelaide, South Australia }\end{array}$ \\
\hline
\end{tabular}




\begin{tabular}{|l|l|l|}
\hline & & University of New South Wales \\
\hline Wong & FACD & The Children's Hospital at Westmead, Sydney, NSW, Australia \\
\hline
\end{tabular}

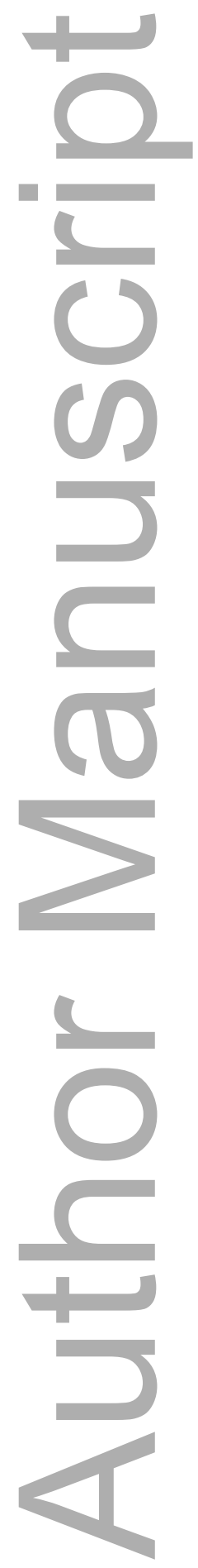

This article is protected by copyright. All rights reserved 
PROF. MARIUS RADEMAKER (Orcid ID : 0000-0003-3393-6748)

DR. ALICIA ANN O'CONNOR (Orcid ID : 0000-0002-2851-3954)

Article type : Review Article

(

Management of Chronic Hand and Foot Eczema. An Australia/New Zealand Clinical Narrative.

Abstract

Chronic hand/foot eczemas are common, but treatment is often challenging, with widespread dissatisfaction over current available options. Detailed history is important, particularly with regard to potential exposure to irritants and allergens. Patch testing should be regarded as a standard investigation.

Individual treatment outcomes and targets, including systemic therapy, should be discussed early with patients; restoring function being the primary goal, with clearing the skin a secondary outcome. Each new treatment, where appropriate, should be considered additive or overlapping to any previous therapy.

Management extends beyond mere pharmacological or physical treatment, and requires an encompassing approach including removal or avoidance of causative factors, behavioural changes and social support. To date, there is little evidence to guide sequences or combinations of therapies.

Moderately symptomatic patients (e.g. DLQI $\geq 10$ ) should be started on a potent/superpotent topical corticosteroid applied once or twice per day for 4 weeks, with tapering to twice weekly application. If response is inadequate, consider phototherapy, and then a 12-week trial of a retinoid (alitretinoin or 
acitretin). Second line systemic treatments include methotrexate, ciclosporin and azathioprine.

For patients presenting with severe symptomatic disease (DLQI $\geq 15$ ), consider predniso(lo)ne $0.5-1.0 \mathrm{mg} / \mathrm{kg} /$ day (or ciclosporin $3-5 \mathrm{mg} / \mathrm{kg} /$ day) for 4-6 weeks with tapering, and then treating as for moderate disease as above. In nonresponders, botulinum toxin and/or iontophoresis, if associated with hyperhidrosis, may sometimes help. Some patients only respond to long-term systemic corticosteroids. The data on sequencing of newer agents, such as dupilumab or JAK inhibitors, is immature.

\section{Introduction}

The management of chronic hand and foot eczema can be challenging. ${ }^{1-5}$ Distinguishing between dermatitis and psoriasis is often difficult, the thickened epidermis, in particular the stratum corneum, restricts percutaneous absorption making topical therapy less effective, and the effects on quality of life are often disproportionate to the area of cutaneous involvement.

Although chronic hand/foot eczemas are common, specific recommendations on their management are sparse..$^{2,3,6,7}$ The Australasian Medical Dermatology Group has developed the following narrative following an in-depth literature review (all languages, search terms included hand eczema/dermatitis, foot eczema/dermatitis, quality of life, reviews, and treatments, including an extensive list of individual drugs and treatment modalities). The narrative is structured around diagnosis, scoring systems, treatment modalities and a discussion on when to treat, what might be considered success, and sequencing of treatments. Specific management of allergic and irritant contact dermatitis of the hands and/or feet were excluded from the discussions, as was general hand/foot care.

\section{Epidemiology and classification}

The prevalence of chronic (i.e., persisting more than 6 months) hand eczema has been estimated at $1-5 \%$, increasing to $10 \%$ if milder cases are included, with an 
incidence of 5.5 cases/1000 person-years. ${ }^{5,8}$ The prevalence is higher in females, perhaps because of traditionally gender-based exposure, for example as hairdressers, nurses, domestic cleaning, food preparation and caregivers. An estimated $5-10 \%$ of hand dermatitis cases are chronic and treatment-resistant. There is very little information on the epidemiology of foot eczema, other than that $30 \%$ of patients with chronic hand eczema also have involvement of the feet., 90

Several studies have assessed the prevalence of subtypes of hand eczema; a UK consensus statement reported that just over half of cases were allergic contact and/or irritant contact dermatitis, with the other common types being atopic hand eczema with or without irritant contact dermatitis, vesicular dermatitis, and hyperkeratotic dermatitis. ${ }^{2}$ Seven categories of hand eczema have been proposed including allergic contact dermatitis, irritant contact dermatitis, endogenous atopic hand eczema alone or in combination, and vesicular and hyperkeratotic types. ${ }^{4,11}$ No specific classification of foot eczema exists.

There is little that is distinctive about the aetiology of non-allergic chronic hand/foot eczema, with contributing factors including barrier dysfunction, genetic changes in filaggrin, a possible role of the skin microbiome, staphylococcal infection, and immune dysregulation.

The morphology of hand/foot eczema can include erythema, oedema, infiltration, scale, hyperkeratosis, fissures and erosions. Vesicular hand/foot eczema may have both acute and chronic features. Acute disease is characterised by recurrent vesicles with or without bullae on a non-erythematous base. Chronic disease has a more inflammatory base, often with a sharp border at the wrists. ${ }^{12}$ Hyperhidrosis and attenuated sweating may be present. ${ }^{13}$ Hyperkeratotic hand eczema has a distinct clinical presentation of sharply demarcated palmar hyperkeratosis with painful fissures. Some consider it to be distinct from hand eczema as it can resemble psoriasis histologically and often responds to psoriasis treatments. ${ }^{14}$

Severe chronic hand eczema interferes with daily activities, social functioning, and 
employment, with a third of patients reporting impairment while working and consequent productivity loss from both presenteeism and absenteeism. ${ }^{15,16}$ The mean annual hand eczema patient cost has been estimated at between $€ 1,712$ to $€ 9,792 .{ }^{17}$ Common symptoms include dryness/flaking (81\%), itchiness (75\%), and cracking/tearing of the skin (71\%), as well as sleep and mood disturbances. ${ }^{16}$

\section{Assessment of chronic hand/foot eczema}

Assessment of chronic hand/foot eczema requires a thorough history, particularly to exclude both irritant and allergic contact dermatitis. The history should include details on onset, evolution, duration, episodic or persistent nature, smoking as a risk factor, occupation, hobbies, family history, and symptoms which may include itching, soreness, cracking, fissuring, bleeding and hyper/hypo-hydrosis. Careful examination of the whole skin should be performed. Patch testing should be considered in all patients.

There is an extensive differential diagnosis, which includes papulosquamous disorders, infections, infestations, neoplasia, physical triggers (mechanical, chemical, thermal), metabolic disease and medications. Dermoscopy may assist the examination (e.g. looking for scabetic burrows); Wood lamp examination, microbiology swabs, skin/nail scrapings for mycology, and total serum IgE should be considered if the inflammation is unresponsive to general measures and first-line treatments. RAST or prick testing should be reserved for suspected cases of protein contact dermatitis. ${ }^{4,6}$ Biopsy is generally unhelpful in distinguishing eczema from psoriasis, but may help with excluding lichen planus or other inflammatory skin conditions.

Once the diagnosis of chronic hand/foot eczema has been made, assessing severity is essential. The ideal clinical scoring system should take into account symptom type and severity, morphology, occupational factors, and quality of life measures including psychological burden, and be able to monitor the effects of treatment. Several groups have reviewed the available scoring systems. ${ }^{18}$ Of these the Hand Eczema Severity Index (HECS), the Hand Eczema Extent Score (HEES), the Quality of 
Life in Hand Eczema Questionnaire (QOLHEQ), and the Patient-Oriented Eczema Measure (POEM) seem most useful. ${ }^{19,20,21,22,23}$ There do not appear to be any specific validated scoring systems for chronic eczema of the feet. The commonly used Eczema Area and Severity Index (EASI), SCORring Atopic Dermatitis (SCORAD) and Dermatology Life Quality Index (DLQI) are less specific for chronic hand/foot eczema.

-

When to treat?

Treatment should be commenced: i) when the patient wants it, for example if there is a high impact on quality of life or function; ii) when the prescribing physician considers there are sufficient symptoms, visible disease, or high-impact disease; and iii) when treatment is available and affordable.

Treatment targets should be discussed, with restoring function being the main goal. Clearing the skin, whilst desirable, should be a secondary outcome. Each new treatment, where appropriate, should be considered additive or overlapping to the previous therapies. As palmoplantar disease can be slow to respond to treatment, each treatment requires a 'fair trial' before considering an alternative; distinguishing between a flare or fluctuation in disease and disease progression can be difficult. To date, there is little evidence to guide sequences or combinations of therapies.

\section{General measures}

Good hand/foot care is an essential first step in the management of chronic hand/foot eczema ${ }^{5}$ and includes skin education programmes, lifestyle changes, and the use of barriers and soap substitutes, despite the evidence base for the latter being weak. Minimising relevant exogenous factors, e.g. exposure to allergens or irritants, is essential, which may require time away from work. Education needs to be repeated at each visit. Patient support and advocacy in the workplace, and interaction with the employer and /or insurers may be required from the treating dermatologist. (see Key points - General). 


\section{$\underline{\text { Topical Treatment }}$}

The use of specific topical therapies is largely based on evidence of their efficacy elsewhere on the skin.

- Emollients: A number of small studies have examined the use of emollients in chronic hand dermatitis. ${ }^{24,25}$ A 3 week trial of a 'medical device repairing emollient cream' reported decreased pain and pruritus at days 8 and 22

- compared to baseline, in $\mathbf{4 0}$ patients with mild to moderate chronic hand dermatitis. ${ }^{26}$ An open-label study of an emulsion containing sucralfate, with copper and zinc sulfates, resulted in patient- and investigator-rated improvements after 7 days in 32 subjects with contact or climatic hand dermatitis. ${ }^{27}$

- Keratolytics: salicylic acid, up to $20 \%$, and urea $10-20 \%$, have often been added to emollients, but the clinical trial evidence is generally of low quality. ${ }^{28} \mathrm{~A}$ barrier strengthening moisturiser containing 5\% urea prolonged the disease free interval of treated hand dermatitis, from 2 days to 20 days, compared to no treatment, in study of 53 patients. ${ }^{29}$

- Topical corticosteroids: After a suitable trial of emollients, barriers, and soap substitutes, potent topical steroids are regarded as the first line pharmacological treatment of moderate/severe hand and foot eczema, despite limited data from randomised, controlled trials to confirm their efficacy. ${ }^{30,31,32}$ Although there are insufficient data on which to base a choice between shortduration potent/super-potent agents, compared with continuous application of less strong corticosteroids, it has been recommended that potent topical corticosteroids be used once daily for 1 month, followed by twice weekly (e.g. at weekends) maintenance therapy. ${ }^{33,34}$ In an open-label study topical mometasone furoate applied freely for up to 9 weeks by patients with hand eczema resulted in clearing at 3 weeks in almost half the patients, and another quarter had cleared at week $6 .{ }^{35}$ Those who had clearing of eczema participated in a trial of maintenance therapy for up to 36 weeks, in which recurrence-free rates were significantly higher in the groups applying glucocorticoid three times weekly (83\%) or twice weekly (68\%) compared to emollients alone (26\%). 
As a general rule once daily application is sufficient; ointment formulations are more effective than creams. There is insufficient evidence of any additive benefit from a combined topical antibacterial/corticosteroid agent.

- Topical calcineurin inhibitors: In 294 patients with chronic hand dermatitis, three weeks of pimecrolimus $1 \%$ cream was associated with a greater improvement in Investigator Global Assessment (IGA) compared to vehicle control. ${ }^{36}$ However, another study in 40 patients found that initial benefit after 3 weeks was not sustained during maintenance therapy. ${ }^{37}$

Studies of tacrolimus are limited by lack of a placebo control, small sample sizes and short duration. A study of 29 adults, ${ }^{38}$ with occupationally-induced hand dermatitis showed complete clearance in $44 \%$ and $\geq 50 \%$ improvement in twothirds of patients (based on the Jena Hand Eczema Score) who used tacrolimus $0.1 \%$ ointment twice daily for 4 weeks. An earlier study of 25 adults with moderate to severe hand and/or foot eczema treated with tacrolimus $0.1 \%$ ointment three times daily for up to 8 weeks reported a significant improvement in a composite severity score. ${ }^{39}$

Alternating a topical corticosteroid with a topical calcineurin inhibitor may reduce adverse events, although the long-term efficacy and safety are unknown.

\section{Other topical agents}

- Bexarotene: In 55 patients with chronic severe hand dermatitis bexarotene gel monotherapy was associated with a $50 \%$ clinical improvement in $79 \%$ of patients and $90 \%$ improvement in $39 \%$ using both a physician assessment score and a modified Hand Eczema Area Severity Score (HEASI). ${ }^{40}$

- Calcipotriol: In 13 patients with chronic hand eczema, 0.005\% calcipotriol ointment was as effective as $0.25 \%$ desoximetasone ointment twice daily for 8 weeks. ${ }^{41}$ Nine patients experienced $\geq 75 \%$ reduction in Hand Eczema Severity Index (HECSI) with calcipotriol. Calcipotriol/betamethasone ointment was used successfully in 3 Chinese patients with chronic hand eczema. ${ }^{42}$

- Coal tar: Tar preparations have long been used for inflammatory skin conditions, but have largely fallen out of favour. Sulfonated shale oils 
(ichthammol) and pine tars are still being used, but with limited clinical trial evidence. $^{43}$

- Crisaborole: Crisaborole, a phosphodiesterase type 4 (PDE4) inhibitor, has been used in the treatment of atopic dermatitis with anecdotal benefit reported in atopic hand dermatitis. ${ }^{44}$

- Delgocitinib: Topical delgocitinib, a pan-Janus kinase (JAK) inhibitor, was

- compared to vehicle ointment in 91 patients with chronic hand eczema, treated for 8 weeks. ${ }^{45}$ More patients receiving delgocitinib (46\%) than vehicle (15\%) achieved treatment success, defined as the proportion achieving clear/almost clear skin with $\geq 2$-point improvement in Physician Global Assessment (PGA).

- Fumaric acid: In a double-blind randomised controlled trial in 58 patients with hand eczema, topical fumaric acid $5 \%$ cream was less effective than triamcinolone $0.05 \%$ cream when used twice daily for one month. ${ }^{46}$

- Retapamulin: A randomised study of 60 adults with hand-foot eczema showed that the addition of retapamulin $1 \%$ ointment, a pleuromutilin antibiotic which targets gram-positive bacteria, to clobetasol propionate $0.05 \%$ foam, was more effective than clobetasol propionate plus vehicle placebo ointment at 14 days, but with no difference at 28 days. ${ }^{47}$

- Bacterial therapy: A double-blind randomised placebo-controlled trial in 75 patients concluded that a cream containing $5 \%$ lysate of the non-pathogenic bacterium Vitroscilla filiformis significantly reduced the severity and pruritus of atopic dermatitis as well as transepidermal water loss and cutaneous colonization by S. aureus. ${ }^{48}$ Commensal strains of coagulase-negative $S$. epidermidis and S. hominis from healthy donors have also been applied to atopic dermatitis skin and found to decrease colonisation by S. aureus. ${ }^{49}$

\section{Physical therapies}

- Phototherapy: Several small trials have shown that ultraviolet B (UVB) may improve chronic hand eczema over a period of 10 weeks, but topical psoralen plus ultraviolet A (PUVA) was superior. ${ }^{2}$ In a 12 week trial of PUVA versus narrow-band UVB (nb-UVB) treatment of palmar hand eczema in 60 patients, 
43\% of the PUVA group achieved PGA 'clear' or 'almost clear' compared to only $23 \%$ in the nb-UVB group. ${ }^{50}$ However, wide confidence intervals suggested PUVA did not achieve clear superiority. Adverse events, mainly erythema, were reported by 9 patients receiving nb-UVB versus none in the PUVA group.

- Excimer laser: A chart review of 30 patients with refractory chronic hand and foot eczema concluded that Excimer laser demonstrated excellent and - sustained efficacy. ${ }^{51}$ The response was assessed using PGA and a modified total lesion/symptom score (mTLSS). The authors stated that compared to other UV therapies, Excimer laser offers lower cumulative doses of UV radiation by targeting specific areas and should be considered alone or in combination with other established or newer therapies.

- Grenz rays: Small case series show some benefits from Grenz rays in the treatment of chronic hand eczema, ${ }^{52,53}$ but a NICE guideline notes the evidence is very limited. ${ }^{54}$ There is some concern about the risk of skin malignancy in the long term, but Grenz remains an option for recalcitrant hyperkeratotic hand eczema.

- Botulinum toxin: In a trial in 10 patients with vesicular hand dermatitis, botulinum toxin A (mean dose - 162 units) was injected in one hand, using the untreated hand as a control. ${ }^{55}$ Self-assessment 5 to 6 weeks later showed that 7 of 10 patients experienced good or very good effect; reported benefits included reduced itch and less severe clinical signs. In a study of 8 patients with dyshidrotic hand eczema, the more severely-affected hand was treated with 100 units of botulinum toxin A, whilst using topical corticosteroids on both hands. ${ }^{56}$ Six patients completed the study. At week 8 the mean Dyshidrotic Eczema Area and Severity Index (DEASI) reduced from 28 to 17 with topical therapy alone and from 36 to 3 with adjuvant botulinum toxin.

- Iontophoresis: In 20 patients with chronic dyshidrotic hand eczema, tap water iontophoresis (15-minute daily treatments over 3 weeks) was performed on one hand, using the untreated hand as a control. ${ }^{13}$ The hand treated with iontophoresis cleared slightly faster (20 vs. 22.3 days; $p=$ not significant); however the relapse-free interval was significantly prolonged at 24.8 weeks 
vs.8.35 weeks for the non-treated hand $(p<0.0001)$. This was confirmed in a larger study of 54 patients with hand/foot eczema. ${ }^{57}$ The authors hypothesise that galvanization with tapwater iontophoresis interrupts the neurogenic inflammation and prolongs the relapse-free interval in hyperhidrotic palmoplantar eczema. Studies also suggest a role for leaky tight junctions in eczema with eccrine sweat leaking into the dermis potentially flaring itch and eczema.

\section{Systemic therapies}

Consideration of systemic therapy should be discussed early with the patient. The traditional immunomodulators azathioprine, ciclosporin, methotrexate and mycophenolate are widely considered second/third-line systemic agents in hand and foot eczema, after topical therapies, phototherapy and retinoids. Their use is based primarily on evidence of their efficacy in atopic dermatitis at other sites. ${ }^{58}$ (see Key points - Specific treatments).

- Systemic corticosteroids: Despite almost no clinical trial data, oral corticosteroids remain very popular in the treatment of chronic hand/foot eczema, in particular for the vesicular subtype. ${ }^{8,16} \mathrm{~A} 2012$ review advised that oral corticosteroids should only be used for one week. ${ }^{3}$ However, in Australia and New Zealand, systemic corticosteroids, 0.5-1 mg/kg/day predniso(lo)ne equivalents is used for up to 4 weeks with dose tapering, similar to the treatment of moderate/severe atopic eczema. ${ }^{57}$

- Acitretin: A number of small trials and case series have demonstrated a benefit of acitretin. Nine patients with severe hand dermatitis received $10-30 \mathrm{mg} /$ day; at 24 weeks a third were clear or almost clear, and $44 \%$ were almost clear or had mild symptoms. ${ }^{59} \mathrm{~A}$ Korean open label study of 28 patients with 2 years of chronic hand dermatitis refractory to high-potency topical corticosteroid were

treated with $10 \mathrm{mg}$ acitretin twice daily for 8 weeks. The Hand Eczema Severity Index (HECSI) fell by 58\%, from 21.9 at baseline to 9.2 , with the hyperkeratotic subtype showing the most improvement. ${ }^{60}$

An 8 week single-blind, placebo-controlled study randomised 29 patients with hyperkeratotic hand eczema to $30 \mathrm{mg} /$ day acitretin or placebo. After 4 weeks 
there was a $51 \%$ reduction in a semi-quantitative score with acitretin (hyperkeratosis, fissuring, scaling, itch, redness and vesicle count) compared to $9 \%$ with placebo. ${ }^{61}$ In a single-blind study of chronic hyperkeratotic palmoplantar dermatitis, 42 patients received either acitretin $25-50 \mathrm{mg} /$ day for 1 month or topical betamethasone/salicylic acid ointment. Using a 10-point severity scale, acitretin was significantly better than the conventional topical treatment after 30 days (two-sided $\mathrm{P}<0.0001$ ) and the improvement persisted for $>5$ months after discontinuing acitretin. ${ }^{62}$

A retrospective review of 17 patients with chronic hand dermatitis treated with either methotrexate or acitretin found that, at 6 months, acitretin achieved clearance/almost clearance in $44 \%$ of patients, compared to none of those treated with methotrexate. At 12 months, 100\% of patients treated with acitretin achieved clearance/almost clearance compared to $40 \%$ of patients treated with methotrexate. Adverse effects were minimal and as expected. ${ }^{63}$ The largest real-world study to date retrospectively reviewed 109 Dutch patients with severe chronic hand eczema treated with acitretin. Patients with hyperkeratotic hand eczema did best: $50.7 \%$ had a good effect. The drug survival rates of acitretin at $12,24,36$, and 52 weeks were $74.3 \%, 45.5 \%, 33.8 \%$ and $23.2 \%$, respectively. ${ }^{64}$ Dose related adverse effects, in particular the teratogenic risks, limits its potential use.

- Alitretinoin: A large randomised placebo controlled trial of 1,032 patients with chronic hand eczema (all types) assessed two dosages of alitretinoin (30 or 10 $\mathrm{mg} /$ day) against placebo, for up to 24 weeks. The percentages of patients rating their hand eczema as 'clear' or 'almost clear' at the end of therapy were 40\%, $24 \%$, and $15 \%$, respectively. ${ }^{65}$ Patients with hyperkeratotic eczema had the highest response rates, but those with vesicular eczema also appeared to benefit. The beneficial effects were confirmed in a retreatment trial among a subgroup of patients who had relapse. ${ }^{66}$ In a real world setting, a quarter (27.4\%) of 95 patients' hand eczema cleared with alitretinoin, with $68.3 \%$ of patients with a hyperkeratotic subtype clearing. The drug survival rates of alitretinoin after $12,24,36$, and 52 weeks were $69.3 \%, 45.1 \%, 19.6 \%$ and $7.0 \%$, respectively. ${ }^{64}$ Multiple other studies report a consistent $40-50 \%$ response 
rate. ${ }^{67-71}$ The response to alitretinoin appears better when combined with potent topical steroids. ${ }^{72}$

A Cochrane review of hand eczema treatments assessed 60 RCTs: 18 topical steroids/calcineurin inhibitors trials, 10 phototherapy, 3 systemic

immunosuppressives, and 5 oral retinoids studies. In total, they included 5,469 participants with mild to severe chronic hand eczema. ${ }^{5}$ The review concluded that alitretinoin $10 \mathrm{mg}$ improves investigator-rated symptom control compared to placebo (risk ratio (RR) 1.58; 95\% Cl 1.20 to 2.07), with numbers needed to treat for an additional beneficial outcome (NNTB) being 11 (95\% Cl 6.3 to 26.5 ). Alitretinoin $30 \mathrm{mg}$ also improves this outcome compared with placebo, RR 2.75 $(95 \% \mathrm{Cl} 2.20$ to 3.43$)$ with a much better NNTB of 4 ( $95 \% \mathrm{Cl} 3$ to 5$)$. Adverse events including headache did not differ between alitretinoin $10 \mathrm{mg}$ and placebo, but the risk of headache increased with alitretinoin $30 \mathrm{mg} .{ }^{73}$ NICE recommends alitretinoin be started when severe disease is present, as defined by the PGA and a DLQI score of $\geq 15$, and stopped as soon as an adequate response has been achieved, or if the eczema remains severe at 12 weeks, or if an adequate response (hands clear or almost clear) has not been achieved by 24 weeks. ${ }^{74}$ Alitretinoin has the usual dose-related retinoid adverse effects; women of childbearing potential need adequate contraception during treatment, and for four weeks after stopping.

- Anti-staphylococcal treatments: Whilst more than half of patients with chronic hand eczema are colonized by Staphylococcus aureus, ${ }^{75,76}$ including methicillinresistant S. aureus (MRSA), ${ }^{77}$ there is little evidence from clinical trials that systemic antibiotics, or decolonisation, are beneficial, particularly as S. aureus counts reduce significantly following monotherapy with topical corticosteroids. ${ }^{78}$

In an open label trial in 30 adult patients with mild to severe chronic hand eczema receiving daily supplementation with Lactobacillus acidophilus, Lactobacillus casei and Lactobacillus rhamnosus for 12 weeks, 5 patients achieved a PGA score of 0 or $1 .{ }^{79}$

- Azathioprine: Azathioprine is used off-label in atopic dermatitis and is generally considered as a third-line option. About one-third of patients with atopic 
dermatitis have a good response, typically after about 6 months. ${ }^{58}$ In an observer-blinded, randomised controlled trial in 91 patients with chronic hand eczema, clobetasol propionate $0.05 \%$ cream in combination with azathioprine $50 \mathrm{mg}$ daily led to significantly higher mean percent improvement in the Hand Eczema Scoring Index (HESCl) at 24 weeks than clobetasol alone (92\% vs. 65\%, $\mathrm{p}=0.001) .{ }^{80}$ In a drug survival study in 30 patients with chronic hand eczema, half discontinued azathioprine in the first 3 months because of adverse effects, but 7 of the 15 patients who continued azathioprine for 3 months, remained on therapy at 1 year. ${ }^{81}$ Concomitant oral corticosteroids were given to 13 patients. The addition of allopurinol to azathioprine may improve clinical response, but the dose of azathioprine should be decreased by $25-50 \% .{ }^{82}$

A head-to-head study of azathioprine and alitretinoin in 116 patients with chronic non-hyperkeratotic hand eczema was due to be completed during 2019.

- Ciclosporin: A head-to-head study compared ciclosporin and topical betamethasone dipropionate $0.05 \%$ for 6 weeks in 41 patients with chronic hand eczema. ${ }^{83}$ The disease activity score decreased to $57 \%$ of baseline in the ciclosporin group and to $58 \%$ in the betamethasone group, suggesting equal effectiveness.

A retrospective review of 102 patients with chronic hand eczema identified an average treatment duration of 10.3 months at doses to $5 \mathrm{mg} / \mathrm{kg} /$ day; two-thirds of patients achieved a PGA of 1 at three months, with the best response in the vesicular subtype, but with a significant rate of side effects and frequent relapses. ${ }^{84} \mathrm{~A}$ more recent open-label study in 16 patients with chronic hand eczema used ciclosporin at a dose of $200 \mathrm{mg} /$ day maintained until $>50 \%$ clearance then tapered to $25-100 \mathrm{mg} /$ day for $10-12$ weeks. ${ }^{85}$ Topical corticosteroids and emollients were permitted. At week 4, 25\% achieved a PGA of 0 and $39 \%$ improved from 'moderate' to 'mild' disease. At week 10, 14 patients had PGA 0 or 1.

In a 24 week, open-label trial of 118 patients with chronic hand eczema comparing alitretinoin and ciclosporin, $68.2 \%$ and $40.9 \%$ respectively, were categorized as responders. ${ }^{86}$ 
- Methotrexate: Despite no reliable data on the use of methotrexate in hand and foot eczema, it is often used as the first additional immunomodulator after topical therapy, phototherapy, retinoids, and systemic corticosteroids. ${ }^{8} \mathrm{~A}$ retrospective review of 42 Dutch patients with chronic hand eczema treated for a median of 139 days found $37 \%$ had a good effect on the Physician Global Assessment (PGA) after 8-12 weeks. ${ }^{87}$

- Mycophenolate mofetil: There are no specific trials of mycophenolate mofetil in the treatment of chronic hand/foot eczema, but this agent has been shown to be of benefit in some patients with atopic dermatitis. ${ }^{58,88}$ Its effectiveness is limited by gastrointestinal side effects, drug interactions and potential teratogenicity.

- Ranitidine: A randomised placebo-controlled trial of ranitidine for the treatment of hand eczema in patients with atopic dermatitis demonstrated benefits of the active treatment using a modified HEASI. ${ }^{89}$

\section{Novel therapies}

- Apremilast: A single case report has described a good response to apremilast in chronic hand eczema. ${ }^{90}$

- Biologics: There is very little information on the use of biologics specifically for hand/foot eczema. A case report describes some efficacy of etanercept in recalcitrant hand pompholyx. ${ }^{91}$

A number of case reports have described the use of dupilumab in chronic hand eczema. A retrospective case series of patients with dermatitis treated with dupilumab identified six with dermatitis involving only the hands and 32 with hand and body involvement. ${ }^{92}$ Diagnoses included dyshidrotic eczema, atopic dermatitis and contact dermatitis. After treatment the Investigator Global Assressment (IGA) of patients with hand dermatitis decreased from 3.3 to 1.7, with $40 \%$ achieving an IGA score of 0 or 1 . Almost all patients with hand dermatitis reported improvement in pruritus, dermatitis-related pain and resolution of fissures.

In an observational prospective study of 47 adult patients with atopic 
dermatitis, who also had hand dermatitis, commenced on dupilumab, HECSI-75 was reached in 28 patients (60\%) by week $16 .{ }^{93,94}$ There are currently no reports of studies of biologics specifically in foot dermatitis

- JAK inhibitors: A number of recent reviews have discussed the potential role of JAK inhibitors in atopic dermatitis but they do not describe their use specifically in hand and foot dermatitis. Anecdotally, as with dupilumab, patients in phase 3 clinical trials of upatacitinib for atopic eczema are showing excellent early responses in their hand/foot dermatitis.

\section{Sequencing of treatments}

The management of hand/foot eczema extends beyond mere pharmacological or physical treatment, and requires an encompassing approach including removal or avoidance of causative factors, behavioural changes and social. ${ }^{7}$ Although several consensus guidelines and treatment algorithms have been proposed, ${ }^{2,3,6,16}$ there are no studies to help recommend sequencing of treatments. The group recommends detailed hand/foot care education, specifically targeting avoidance of irritants and potential allergens, at each visit. Patients should be informed of the importance of application of liberal amounts of emollients and barrier creams.

Moderately symptomatic patients (e.g. DLQI $\geq 10$ ) should be started on a potent/super-potent topical corticosteroids applied once or twice per day for 4 weeks, with tapering to twice weekly (or at weekends) if adequate response is achieved. If no significant improvement, consideration should be given to adding phototherapy (if available). If inadequate response to phototherapy within 4-6 weeks, or phototherapy is not available, a trial of alitretinoin $30 \mathrm{mg} /$ day should be considered. If alitretinoin is not available, acitretin $10-30 \mathrm{mg} /$ day may be considered as an alternative. When pregnancy is a concern, ciclosporin may be considered in at risk female patients. If there is limited response to retinoids after 12 weeks, the addition of a conventional systemic immunomodulator may be appropriate; there was some disparity within the group, with the addition of methotrexate slightly preferred over ciclosporin and then azathioprine. These should be used in accordance with experience gained from atopic dermatitis. ${ }^{58}$ 
For patients presenting with severe symptomatic disease (DLQI $\geq 15$ ), consider predniso(lo)ne 0.5-1.0 mg/kg/day for 4-6 weeks (or ciclosporin $3-5 \mathrm{mg} / \mathrm{kg} / \mathrm{day}$ ), and then treating as for moderate disease described above. In non-responders, if significant hyperhidrosis is present, consider botulin toxin or iontophoresis. Some patients only respond to systemic corticosteroids, which may need to be continued long term. The data on sequencing of newer agents, such as dupilumab or JAK inhibitors, is still immature.

In case of no response, reconsider the diagnosis with repeat patch testing including for topical corticosteroids and assessing microbiology/mycology. Consider an empirical course of anti-staphylococcal therapy (e.g. flucloxacillin).

\section{How to measure success}

Success should be measured by improvement in patient symptoms. Although DLQI is not ideal for measuring response, it is the most widely used patient reported outcome measure. The minimum clinically important difference is a reduction of DLQI by 4 , but ideally the DLQI target should be an absolute score of below 5 . A patient specific outcome should also be negotiated, e.g. able to shampoo hair without discomfort, be able to play a round of golf, be able to access fingerprint scanning on their cell phone, etc.

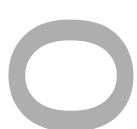

\section{References}

1. Agner T, Elsner P. Hand eczema: epidemiology, prognosis and prevention. J Eur Acad Dermatol Venereol. 2020;34 Suppl 1:4-12.

2. English J, Aldridge R, Gawkrodger DJ et al. Consensus statement on the management of chronic hand eczema. Clin Exp Dermatol. 2009;34:761-9.

3. Coenraads PJ. Hand eczema. N Engl J Med. 2012;367:1829-37.

4. Diepgen TL, Andersen KE, Brandao FM et al. Hand eczema classification: a crosssectional, multicentre study of the aetiology and morphology of hand eczema. Br J Dermatol. 2009;160:353-8. 
5. Christoffers WA, Coenraads PJ, Svensson Å et al. Interventions for hand eczema. Cochrane Database of Systematic Reviews 2019, Issue 4. Art. No.: CD004055.

6. Diepgen TL, Andersen KE, Chosidow O et al. Guidelines for diagnosis, prevention and treatment of hand eczema. J Dtsch Dermatol Ges. 2015;13:e1-e22.

7. Elsner P, Agner T. Hand eczema: treatment. J Eur Acad Dermatol Venereol. 2020;34 Suppl 1:13-21.

8. Smith IL, Brown S, Nixon J et al. Treatment of severe, chronic hand eczema: results from a UK-wide survey. Clin Exp Dermatol 2017;42:185-8.

9. Agner T, Aalto-Korte K, Andersen KE, Foti C, Gimenez-Arnau A, Goncalo M, et al. Factors associated with combined hand and foot eczema. J Eur Acad Dermatol Venereol. 2017;31:828-32.

10. Brans R, Hübner A, Gediga G, John SM Prevalence of foot eczema and associated occupational and non-occupational factors in patients with hand eczema. Contact Dermatitis. 2015;73:100-7.

11. Molin S, Diepgen TL, Ruzicka T, Prinz JC. Diagnosing chronic hand eczema by an algorithm: a tool for classification in clinical practice. Clin Exp Dermatol.

2011;36:595-601.

12. Warshaw EM. Therapeutic options for chronic hand dermatitis. Dermatol Ther. 2004;17:240-50.

13. Odia S, Vocks E, Rakoski J, Ring J. Successful treatment of dyshidrotic hand eczema using tap water iontophoresis with pulsed direct current. Acta Derm Venereol. 1996;76:472-4.

14. Park JY, Cho EB, Park EJ et al. The histopathological differentiation between palmar psoriasis and hand eczema: A retrospective review of 96 cases. J Am Acad Dermatol. 2017;77:130-5.

15. Agner T, Andersen KE, Brandao FM, Bruynzeel DP, Bruze M, Frosch P, Goncalo M, Goossens A, Le Coz CJ, Rustemeyer T, White IR, Diepgen T; EECDRG. Hand eczema severity and quality of life: a cross-sectional, multicentre study of hand eczema patients. Contact Dermatitis. 2008;59:43-7.

16. Dibenedetti D, Baranowski E, Zelt S, Reynolds M, Sherrill B. Assessing United States Patient and Dermatologist Experiences with Severe Chronic Hand Eczema. J Clin Aesthet Dermatol. 2015;8:19-27. 
17. Politiek K, Oosterhaven JA, Vermeulen KM, Schuttelaar ML. Systematic review of cost-of-illness studies in hand eczema. Contact Dermatitis. 2016;75:67-76.

18. Rönsch H, Apfelbacher C, Brans R, Matterne U, Molin S, Ofenloch R, Oosterhaven JAF, Schuttelaar MLA, Weisshaar E, Yew YW, Bauer A. Which outcomes have been measured in hand eczema trials? A systematic review. Contact Dermatitis. 2019;80:201-7.

19. van der Valk PG, van Gils RF, Boot CR et al. A simple tool with which to study the course of chronic hand eczema in clinical practice: a reduced-item score. Contact Dermatitis. 2013;69:112-7.

20. Lindberg M, Bingefors K, Meding B, Berg M. Hand eczema and health-related quality of life; a comparison of EQ-5D and the Dermatology Life Quality Index (DLQI) in relation to the Hand Eczema Extent Score (HEES). Contact Dermatitis. 2013;69:138-43.

21. Josefson A, Berg M, Gånemo A et al. Methodological aspects of assessing hand eczema: comparison of two tools and three different categories of evaluators. $\mathrm{Br} \mathrm{J}$ Dermatol. 2017;176:1373-5.

22. Barrett A, Hahn-Pedersen J, Kragh N, Evans E, Gnanasakthy A. Patient-Reported Outcome Measures in Atopic Dermatitis and Chronic Hand Eczema in Adults. Patient. 2019;12:445-59.

23. Oosterhaven JAF, Ofenloch RF, Schuttelaar MLA. Interpretability of the Quality Of Life in Hand Eczema Questionnaire. J Invest Dermatol. 2019 Oct 10. doi: 10.1016/j.jid.2019.08.450

24. Kucharekova M, Van De Kerkhof PC, Van Der Valk PG. A randomized comparison of an emollient containing skin-related lipids with a petrolatum-based emollient as adjunct in the treatment of chronic hand dermatitis. Contact Dermatitis. 2003;48:293-9.

25. Varothai S, Winayanuwattikun W, Phaitoonwattanakij S, Kasemsarn P, Boonchai W. An investigator-blinded, randomized, prospective, comparative study of efficacy of four anti-inflammatory and barrier hand moisturizers in patients with chronic hand dermatitis. Dermatol Ther. 2018;31:e12670. 
26. Thouvenin MD, Bacquey A, Nocera T, Rossi AB. Tolerability and efficacy of a medical device repairing emollient cream in adults with chronic hand dermatitis. J Cosmet Dermato.I 2018;17:1158-64.

27. Ribet V, Mielewczyk E, Sirvent A et al. A novel dermo-cosmetic product containing thermal spring water, sucralfate, copper sulfate, and zinc sulfate in the management of hand eczema. Clin Cosmet Investig Dermatol. 2018;11:373-81.

28. Fredriksson T, Gip L. Urea creams in the treatment of dry skin and hand dermatitis. Int J Dermatol. 1975;14:442-4.

29. Lodén M, Wirén K, Smerud K, et al. Treatment With a Barrier-Strengthening Moisturizer Prevents Relapse of Hand-Eczema. An Open, Randomized, Prospective, Parallel Group Study. Acta Derm Venereol. 2010;90:602-6.

30. Gola M, D'Erme AM, Milanesi N. Clinical efficacy of two topical corticosteroids in the management of chronic hand eczema. G Ital Dermatol Venereol. 2015;150:2936.

31. Goh CL, Lim JT, Leow YH, Ang CB, Kohar YM. The therapeutic efficacy of mometasone furoate cream $0.1 \%$ applied once daily vs clobetasol propionate cream 0.05\% applied twice daily in chronic eczema. Singapore Med J. 1999;40:3414.

32. Faghihi G, Iraji F, Shahingohar A, Saidat A. The efficacy of ' $0.05 \%$ Clobetasol + $2.5 \%$ zinc sulphate' cream vs. ' $0.05 \%$ Clobetasol alone' cream in the treatment of the chronic hand eczema: a double-blind study. J Eur Acad Dermatol Venereol. 2008;22:531-6.

33. Drake LA, Dinehart SM, Farmer ER, et al. Guidelines of care for the use of topical glucocorticosteroids. J Am Acad Dermatol.1996;35:615-9.

34. Möller H, Svartholm H, Dahl G. Intermittent maintenance therapy in chronic hand eczema with clobetasol propionate and flupredniden acetate. Curr Med Res Opin. 1983;8:640-4.

35. Veien NK, Olholm Larsen P, Thestrup-Pedersen K, Schou G. Long-term, intermittent treatment of chronic hand eczema with mometasone furoate. $\mathrm{Br} \mathrm{J}$ Dermatol. 1999;140:882-6.

36. Belsito DV, Fowler JF Jr, Marks JG Jr et al. Pimecrolimus cream 1\%: a potential new treatment for chronic hand dermatitis. Cutis. 2004;73:31-8. 
37. Bauer A, Lange $N$, Matterne $U$ et al. Efficacy of pimecrolimus $1 \%$ cream in the long term management of atopic hand dermatitis. A double-blind RCT. J Dtsch Dermatol Ges. 2012;10:426-33.

38. Schliemann S, Kelterer D, Bauer A et al. Tacrolimus ointment in the treatment of occupationally induced chronic hand dermatitis. Contact Dermatitis. 2008;58:299306.

39. Thelmo MC, Lang W, Brooke E, Osborne BE, McCarty MA, Jorizzo JL, Fleischer A Jr. An open-label pilot study to evaluate the safety and efficacy of topically applied tacrolimus ointment for the treatment of hand and/or foot eczema. J Dermatolog Treat. 2003;14:136-40.

40. Hanifin JM, Stevens V, Sheth P, Breneman D. Novel treatment of chronic severe hand dermatitis with bexarotene gel. Br J Dermatol. 2004;150:545-53.

41. Juntongjin P, Pongprasert R. Calcipotriol ointment shows comparable efficacy to topical steroids in chronic hand eczema. Dermatol Ther. 2019;32:e12956.

42. Yang M, Chang JM. Successful treatment of refractory chronic hand eczema with calcipotriol/betamethasone ointment: A report of three cases. Exp Ther Med. 2015;10:1943-6.

43. Schmid MH, Korting HC. Coal tar, pine tar and sulfonated shale oil preparations: comparative activity, efficacy and safety. Dermatology. 1996;193:1-5.

44. Yang H, Wang J, Zhang X, Zhang Y, Qin ZL, Wang H, Luo XY. Application of Topical Phosphodiesterase 4 Inhibitors in Mild to Moderate Atopic Dermatitis: A Systematic Review and Meta-analysis. JAMA Dermatol. 2019;155:585-93.

45. Worm M, Bauer A, Elsner P et al. Efficacy and safety of topical delgocitinib in patients with chronic hand eczema: data from a randomized, double-blind, vehiclecontrolled phase Ila study. Br J Dermatol. 2019 Aug 29. doi: 10.1111/bjd.18469. 46. Jowkar F, Saki N, Mokhtarpour A, Saki MR. Comparison of fumaric acid 5\% cream versus triamcinolone $0.1 \%$ cream in the treatment of hand eczema. Acta Med Iran. 2014;52:528-31.

47. Haddican M, Linkner RV, Singer $G$ et al. Retapamulin $1 \%$ ointment and clobetasol propionate $0.05 \%$ foam is more efficacious than vehicle ointment and clobetasol $0.05 \%$ propionate foam in the treatment of hand/foot dermatitis: a 
single center, randomized, double-blind study. J Clin Aesthet Dermatol. 2014;7:32-

6.

48. Gueniche A, Knaudt B, Schuck E, Volz T, Bastien P, Martin R, Röcken M, Breton L, Biedermann T. Effects of nonpathogenic gram-negative bacterium Vitreoscilla filiformis lysate on atopic dermatitis: a prospective, randomized, double-blind, placebo-controlled clinical study. Br J Dermatol. 2008;159:1357-63.

49. Nakatsuji T, Chen TH, Narala S et al. Antimicrobials from human skin commensal bacteria protect against Staphylococcus aureus and are deficient in atopic dermatitis. Sci Transl Med. 2017 Feb 22;9(378).

50. Brass D, Farr P, Reynolds $\mathrm{N}$ et al. An observer-blinded randomized controlled pilot study comparing localised psoralen-ultraviolet $A$ with localized narrowband ultraviolet B for the treatment of hand eczema. Br J Dermatol. 2018;179:63-71. 51. Shroff A, Malajian D, Czarnowicki T et al. Use of $308 \mathrm{~nm}$ excimer laser for the treatment of chronic hand and foot eczema. Int J Dermatol. 2016;55:e447-53.

52. Fenton L, Dawe RS. Six years' experience of grenz ray therapy for the treatment of inflammatory skin conditions. Clin Exp Dermatol. 2016;41:864-70.

53. Duff M, Cruchfield CE 3rd, Moore J, Farniok K, Potish RA, Gallego H. Radiation therapy for chronic vesicular hand dermatitis. Dermatitis. 2006;17:128-32.

54. NICE - National Institute for Health and Care Excellence. Grenz rays therapy for inflammatory skin conditions. Interventional procedures guidance [IPG236] Published date: November 2007

55. Swartling C, Naver H, Lindberg M, Anveden I. Treatment of dyshidrotic hand dermatitis with intradermal botulinum toxin. J Am Acad Dermatol. 2002;47:667-71. 56. Wollina U, Karamfilov T. Adjuvant botulinum toxin A in dyshidrotic hand eczema: a controlled prospective pilot study with left-right comparison. J Eur Acad Dermatol Venereol. 2002;16:40-2.

57. Wollina U, Uhlemann C, Elstermann D, Köber L, Barta U. Therapy of hyperhidrosis with tap water iontophoresis. Positive effect on healing time and lack of recurrence in hand-foot eczema. Hautarzt. 1998;49:109-13.

58. Rademaker M, Agnew K, Andrews M et al. Managing atopic dermatitis with systemic therapies in adults and adolescents: An Australian/New Zealand narrative. Australas J Dermatol. 2020;61:9-22. 
59. Tan J, Maari C, Nigen S, Bolduc C, Bissonnette R. Open label exploratory study of acitretin for the treatment of severe chronic hand dermatitis. J Dermatolog Treat. 2015;26:373-5.

60. Song M, Lee HJ, Lee WK et al. Acitretin as a Therapeutic Option for Chronic Hand Eczema. Ann Dermatol. 2017;29:385-7.

61. Thestrup-Pedersen K, Andersen KE et al. Treatment of hyperkeratotic dermatitis of the palms (eczema keratoticum) with oral acitretin: a single blind placebocontrolled study. Acta Derm Venereol. 2001;81:353-5.

62. Capella GL, Fracchiolla C, Frigerio E, Altomare G. A controlled study of comparative efficacy of oral retinoids and topical betamethasone/salicylic acid for chronic hyperkeratotic palmoplantar dermatitis. J Dermatolog Treat. 2004;15:8893.

63. O'Shea PM, Lugo-Somolinos A. Methotrexate versus Acitretin in the Treatment of Chronic Hand Dermatitis. J Drugs Dermatol. 2015;14:1389-91.

64. Politiek K, Christoffers WA, Coenraads PJ, Schuttelaar MA. Alitretinoin and acitretin in severe chronic hand eczema; results from a retrospective daily practice study. Dermatol Ther. 2016;29:364-71.

65. Ruzicka T, Lynde CW, Jemec GB et al. Efficacy and safety of oral alitretinoin (9cis retinoic acid) in patients with severe chronic hand eczema refractory to topical corticosteroids: results of a randomized, double-blind, placebo-controlled, multicentre trial. Br J Dermatol. 2008;158:808-17.

66. Bissonnette R, Worm M, Gerlach B et al. Successful retreatment with alitretinoin in patients with relapsed chronic hand eczema. Br J Dermatol. 2010;162:420-6.

67. Augustin $M$, Thaçi $D$, Kamps A. Impact on quality of life of alitretinoin in severe chronic hand eczema: FUGETTA real-world study. J Dtsch Dermatol Ges. 2016;14:1261-70.

68. Diepgen TL, Pfarr E, Zimmermann T. Efficacy and tolerability of alitretinoin for chronic hand eczema under daily practice conditions: results of the TOCCATA open study comprising 680 patients. Acta Derm Venereol. 2012;92:251-5.

69. Fowler JF, Graff O, Hamedani AG. A phase 3, randomized, double-blind, placebo-controlled study evaluating the efficacy and safety of alitretinoin (BAL4079) 
in the treatment of severe chronic hand eczema refractory to potent topical corticosteroid therapy. J Drugs Dermatol. 2014;13:1198-204.

70. Lynde C, Cambazard F, Ruzicka T et al. Extended treatment with oral alitretinoin for patients with chronic hand eczema not fully responding to initial treatment. Clin Exp Dermatol. 2012;37:712-7.

71. Thaçi D, Augustin M, Westermayer B et al. Effectiveness of alitretinoin in severe chronic hand eczema: PASSION, a real-world observational study. J Dermatolog Treat. 2016;27:577-83.

72. Cheon DU, Kim JE, Ko JY, Ro YS. Efficacy of alitretinoin depending on the concomitant use of topical corticosteroids in chronic hand eczema patients. J Dermatol. 2019;46:998-1005

73. Morris M, Schifano L, Fong R, Graff O. Safety of alitretinoin for severe refractory chronic hand eczema: Clinical studies and postmarketing surveillance. J Dermatolog Treat. 2016;27:54-8.

74. National Institute for Health and Care Excellence. Alitretinoin for the treatment of severe chronic hand eczema. 2009. http://www. nice.org.uk/guidance/ta177. 75. Haslund P, Bangsgaard N, Jarløv JO et al. Staphylococcus aureus and hand eczema severity. Br J Dermatol. 2009;161:772-7.

76. Mernelius S, Carlsson E, Henricson J et al. Staphylococcus aureus colonization related to severity of hand eczema. Eur J Clin Microbiol Infect Dis. 2016;35:1355-61. 77. Chen Y, Wang X, Zhang C, Shi W. Detection and treatment of Staphylococcus aureus colonization in chronic hand eczema: a multicenter study. J Dermatolog Treat. 2019;30:565-7.

78. Nilsson E, Henning C, Hjörleifsson ML. Density of the microflora in hand eczema before and after topical treatment with a potent corticosteroid. J Am Acad Dermatol. 1986;15(2 Pt 1):192-7.

79. Gulliver WP, Hutton AS, Ship N. Investigating the therapeutic potential of a probiotic in a clinical population with chronic hand dermatitis. Clin Cosmet Investig Dermatol. 2018;11:265-71.

80. Agarwal US, Besarwal RK. Topical clobetasol propionate $0.05 \%$ cream alone and in combination with azathioprine in patients with chronic hand eczema: an observer 
blinded randomized comparative trial. Indian J Dermatol Venereol Leprol. 2013;79:101-3.

81. Oosterhaven JA, Politiek K, Schuttelaar MA. Azathioprine treatment and drug survival in patients with chronic hand eczema - results from daily practice. Contact Dermatitis. 2017;76:304-7.

82.Garritsen FM, van der Schaft J, de Graaf M et al. Allopurinol co-prescription improves the outcome of azathioprine treatment in chronic eczema. Acta Derm Venereol. 2018;98:373-5.

83. Granlund H, Erkko P, Reitamo S. Comparison of the influence of cyclosporine and topical betamethasone-17,21-dipropionate treatment on quality of life in chronic hand eczema. Acta Derm Venereol. 1997;77:54-8.

84. Christoffers WA, Politiek K, Coenraads PJ et al. Drug survival of cyclosporine in the treatment of hand eczema: a multicentre, daily use study. J Eur Acad Dermatol Venereol. 2016;30:63-6.

85. Kim HL, Jung HJ, Park MY, Youn JI, Ahn JY. Clinical Efficacy of Oral Cyclosporine on Intractable Hand Eczema: A Retrospective Review of 16 Cases. Ann Dermatol. 2018;30:475-8.

86. Jang YJ, Yoon JH, Park EJ, Kim KJ, Kim KH. Efficacy and Safety of Treatment with Oral Alitretinoin and Oral Cyclosporine for Chronic Hand Eczema: A Retrospective Review of 118 Cases. Acta Derm Venereol. 2020 Jan 30;100(1):adv00043.

87. Politiek K, van der Schaft J, Christoffers WA et al. Drug survival of methotrexate treatment in hand eczema patients: results from a retrospective daily practice study. J Eur Acad Dermatol Venereol. 2016;30:1405-7.

88. Phan K, Smith SD. Mycophenolate mofetil and atopic dermatitis: systematic review and meta-analysis. J Dermatolog Treat. 2019 Aug 1:1-5. doi:

10.1080/09546634.2019.1642996.

89. Veien NK, Kaaber K, Larsen PO et al. Ranitidine treatment of hand eczema in patients with atopic dermatitis: a double-blind, placebo-controlled trial. J Am Acad Dermatol. 1995;32:1056-7.

90. Navarro-Triviño FJ, Cuenca-Barrales C, Vega-Castillo JJ, Ruiz-Villaverde R. Chronic hand eczema and hepatogenic pruritus with good response to apremilast. Dermatol Ther. 2019;32:e12879. 
91. Ogden S, Clayton TH, Goodfield MJ. Recalcitrant hand pompholyx: variable response to etanercept. Clin Exp Dermatol. 2006;31:145-6.

92. Lee N, Chipalkatti N, Zancanaro $P$ et al. A retrospective review of dupilumab for hand dermatitis. Dermatology. 2019;235:187-8.

93. Oosterhaven JAF, Romeijn GLE, Schuttelaar MLA. Dupilumab Treatment of Very Severe Refractory Atopic Hand Eczema. JAMA Dermatol. 2018;154:969-70.

94. Oosterhaven JAF, Voorberg AN, Romeijn GLE, et al. Effect of dupilumab on hand eczema in patients with atopic dermatitis: An observational study. J Dermatology. 2019 Jun 12. doi: $10.1111 / 1346-8138.14982$.

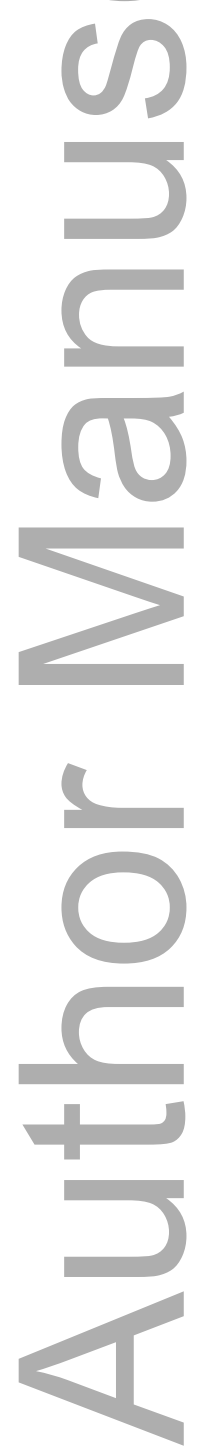

This article is protected by copyright. All rights reserved 


\section{University Library}

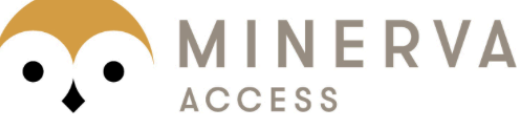

A gateway to Melbourne's research publications

Minerva Access is the Institutional Repository of The University of Melbourne

Author/s:

Rademaker, M;Armour, K;Baker, C;Foley, P;Gebauer, K;Gupta, M;Marshman, G;O'Connor, A;Rubel, D;Sullivan, J;Wong, L-C

Title:

Management of chronic hand and foot eczema. An Australia/New Zealand Clinical narrative

Date:

2020-08-10

Citation:

Rademaker, M., Armour, K., Baker, C., Foley, P., Gebauer, K., Gupta, M., Marshman, G., O'Connor, A., Rubel, D., Sullivan, J. \& Wong, L. -C. (2020). Management of chronic hand and foot eczema. An Australia/New Zealand Clinical narrative. AUSTRALASIAN JOURNAL OF DERMATOLOGY, 62 (1), pp.17-26. https://doi.org/10.1111/ajd.13418.

Persistent Link:

http://hdl.handle.net/11343/276134 